\title{
Correction to: The use of endoluminal techniques in the revision of primary bariatric surgery procedures: a systematic review
}

\author{
Yan Mei Goh ${ }^{1,2} \cdot$ Nicole Ellen James $^{1} \cdot$ En Lin Goh $^{1,3} \cdot$ Achal Khanna $^{2}$
}

Published online: 13 March 2020

○) Springer Science+Business Media, LLC, part of Springer Nature 2020

\section{Correction to: Surgical Endoscopy}

https://doi.org/10.1007/s00464-020-07468-w

This article was updated to correct Yan Mei Goh's name ("Miss" was deleted); it is correct as displayed here.

Publisher's Note Springer Nature remains neutral with regard to jurisdictional claims in published maps and institutional affiliations.

The original article can be found online at https://doi.org/10.1007/ s00464-020-07468-w.

Yan Mei Goh

yanmei.goh@doctors.org.uk

1 Imperial College London, London, UK

2 Department of General Surgery, Milton Keynes University Hospital, Milton Keynes, UK

3 Oxford University Hospitals NHS Foundation Trust, Oxford, UK 